\title{
Prediagnostic plasma concentrations of organochlorines and risk of B-cell non- Hodgkin lymphoma in envirogenomarkers: a nested case-control study
}

Rachel S. Kelly ${ }^{1,2^{*}}$, Hannu Kiviranta ${ }^{3}$, Ingvar A. Bergdahl ${ }^{4}$, Domenico Palli ${ }^{5}$, Ann-Sofie Johansson ${ }^{6}$, Maria Botsivali ${ }^{7}$, Paolo Vineis ${ }^{2,8}$, Roel Vermeulen ${ }^{9}$, Soterios A. Kyrtopoulos ${ }^{7}$, Marc Chadeau-Hyam ${ }^{2}$ and on behalf of the EnviroGeno Markers project consortium

\begin{abstract}
Background: Evidence suggests a largely environmental component to non-Hodgkin's lymphoma (NHL). Persistent organic pollutants (POPs) including polychlorinated biphenyls (PCBs), DDE and HCB have been repeatedly implicated, but the literature is inconsistent and a causal relationship remains to be determined.

Methods: The EnviroGenoMarkers study is nested within two prospective cohorts EPIC-Italy and the Northern Sweden Health and Disease Study. Six PCB congeners, DDE and HCB were measured in blood plasma samples provided at recruitment using gas-chromatography mass spectrometry. During 16 years follow-up 270 incident cases of B-cell $\mathrm{NHL}$ (including 76 cases of multiple myeloma) were diagnosed. Cases were matched to 270 healthy controls by centre, age, gender and date of blood collection. Cases were categorised into ordered quartiles of exposure for each POP based on the distribution of exposure in the control population. Logistic regression was applied to assess the association with risk, multivariate and stratified analyses were performed to identify confounders or effect modifiers.

Results: The exposures displayed a strong degree of correlation, particularly amongst those PCBs with similar degrees of chlorination. There was no significant difference $(p<0.05)$ in median exposure levels between cases and controls for any of the investigated exposures. However under a multivariate model PCB138, PCB153, HCB and DDE displayed significant inverse trends (Wald test $p$-value $<0.05$ ). Under stratified analyses these were determined to be driven by males and by the Diffuse Large B-Cell Lymphoma subtype. When considering those in the highest levels of exposure $\left(>90^{\text {th }}\right.$ percentile) the association was null for all POPs

Conclusion: We report no evidence that a higher body burden of PCBs, DDE or HCB increased the risk of subsequent $\mathrm{NHL}$ diagnosis. Significantly inverse associations were noted for males with a number of the investigated POPs. We hypothesize these unexpected relationships may relate to the subtype composition of our population, effect modification by BMl or other unmeasured confounding. This study provides no additional support for the previously observed role of PCBs, DDE and HCB as risk factors for NHL.
\end{abstract}

Keywords: Non Hodgkin lymphoma, Polychlorinated biphenyls, DDE, HCB, Organochlorines, EnviroGenoMarkers

\footnotetext{
* Correspondence: hprke@channing.harvard.edu

${ }^{1}$ Channing Division of Network Medicine, Department of Medicine, Brigham and Women's Hospital and Harvard Medical School, 181 Longwood Avenue, Boston, MA 02115, USA

${ }^{2}$ Department of Epidemiology and Biostatistics, Imperial College London,

London, UK

Full list of author information is available at the end of the article
} 


\section{Background}

The non-Hodgkin's lymphomas (NHL) are a heterogeneous collection of lymphoproliferative B or T-cell malignancies that typically present as a solid tumour of lymphoid cells in the glands [1]. Currently more than 50 different subtypes of B and T-cell NHL have been defined, differing in both clinic-pathological and biological characteristics [2]. Yet despite their widespread prevalence and high mortality rate, relatively little is known about the aetiology of NHL [3].

Immune dysfunction is the underlying basis of lymphomagenesis and the most well established risk factor to date is immunosuppression [4-6]. However immunosuppressed patients in fact account for only a small fraction of cases, and the epidemiological evidence suggests a largely environmental component to the aetiology of NHL [7]. The reported increase in incidence of NHL, and particularly of the more highly aggressive subtypes, in the UK and most other Western countries since the 1980s had been noted to mirror the worldwide usage trends of a number of suspected chemical risk factors, including polychlorinated biphenyls (PCBs). A plateauing of this increase was observed to occur following the banning of many of these substances in much of the world [8]. Similarly, an excess of cases has been reported in those who are occupationally or residentially exposed to the suggested environmental risk factors [9]. However, the literature is inconsistent and to date, few definitive environmental risk factors for NHL have been agreed upon

The EnviroGenoMarkers project [10] is a nested casecontrol study within two cohorts with prospectively collected blood samples. The study aimed at the development and application of a new generation of biomarkers to aid the study of the role of environmental agents in disease. It utilises the large-scale application of multiple -omics technologies to validate novel predictive disease biomarkers and to explore the association of these biomarkers with environmental pollutants using the "meet-in-the-middle" approach [11]. "meet-in-the-middle" employs parallel analysis of exposure-biomarker relationships and metabolitebiomarker relationships, in an attempt to understand the causal pathway. The first step of this approach is to determine the exposure-disease relationship. The aim of this present study was to determine the association between NHL and prediagnositic blood plasma concentrations of ten environmental pollutants including six PCB congeners, DDT, DDE, HCB and BDE-47.

\section{Methods}

\section{Study subjects}

The EnviroGenoMarkers study is based on 540 participants from two existing prospective cohort studies: EPIC-Italy $(n=168)$ [12] and the Northern Sweden
Health and Disease Study (NSHDS, $n=372$ ) [13] which have been described in detail previously. This study was approved by the committee on research ethics at the relevant institutions in accordance with the Declaration of Helsinki of the World Medical Association. All participants signed an informed consent form agreeing to provide detailed information on their dietary and life-style habits at recruitment and to provide blood samples for use in future research.

Both cohorts recruited healthy volunteers who underwent standardised protocols including detailed questionnaires, anthropometric measurements, medical record review and collection of blood samples. Recruitment for EPIC-Italy took place between 1993 and 1998, and for the NSHDS between 1990 and 2006. In EPIC-Italy standardized procedures were used to identify newly diagnosed cases of cancer based on automated linkages to cancer and mortality registries, municipal population offices and hospital discharge systems, with the exception of Naples where follow up information was collected through periodic personal contact. In the NSHDS invasive cancers were identified by linkage with the Swedish Cancer Registry and the local Northern Sweden Cancer Registry.

For each lymphoma case that occurred within up to 16 years follow up a suitable cancer-free control was selected by incidence matching on sex, age (+/ -2.5 years), centre and date of blood extraction ( $+/-6$ months) from the remaining cancer-free populations. More than $95 \%$ of participants also had the same fasting status as their matched pair at blood extraction. Information from the two studies was integrated into a single database and calibrated. Lymphoma cases were classified into subtypes according to the SEER ICD-0-3 morphology codes [14].

\section{Exposure assessment}

Exposure to persistent organic pollutants (POPs) was assessed using blood plasma. Blood samples were collected in citrate (EPIC-Italy) or heparin (NSHDS) tubes and processed by centrifugation on the day of collection (EPIC-Italy) or within one hour of collection (NSHDS). Aliquots $(0.5 \mathrm{ml})$ were stored in liquid nitrogen tanks at $-196{ }^{\circ} \mathrm{C}$ in Italy and $-80^{\circ} \mathrm{C}$ in NSHDS.

All samples were measured at the National Institute for Health and Welfare Chemicals and Health Unit, Neulanen Research Centre, Finland The quantification of POPs was performed by an Agilent 6890 gas chromatograph (GC) connected to a Waters Autospec Ultima high resolution mass spectrometer (HRMS). The GC column used was DB-5MS (J\&W Scientific, $30 \mathrm{~m}$, ID $0.25 \mathrm{~mm}, 0.25 \mu \mathrm{m}$ ), and the splitless mode was used for injection. For 43 EPIC-Italy matched pairs a slightly different procedure was used involving an Agilent 7000B gas chromatography triple quadruple mass spectrometry 
(GC-MS/MS) system, with a DB-5MS UI (J\&W Scientific, $20 \mathrm{~m}$, ID $0.18 \mathrm{~mm}, 0.18 \mu \mathrm{m}) \mathrm{GC}$ column and the solvent vent mode. For quality control purposes in each batch of samples (43 batches with HRMS, 20 batches with $\mathrm{MS} / \mathrm{MS}$ ) two reagent blanks were additionally prepared and the average result of the blank samples subtracted from the results of the real samples. Furthermore two control samples of Standard Reference Material 1589a (PCBs, Pesticides, BDEs, Dioxins/Furans in Humans) from the National Institute of Standards and Technology, were also included in each batch. Unadjusted volume-based concentrations of POPs, which have been found to correlate well with lipid based concentrations, are presented [15].

\section{Statistical analysis}

All analyses were conducted on the total population as well as stratified by cohort (EPIC-Italy and NSHDS) and by sex where appropriate. The differences in baseline characteristics between cases and controls were determined using Student's $t$-test and chi-squared test for continuous outcomes and categorical outcomes respectively.

Exposure concentrations were explored using nonparametric methods due to their typically non-Gaussian distributions. Differences in concentrations between the cohorts and by sex specific analyses were assessed using the ranksum test while the differences between cases and controls were assessed using the Wilcoxon signed rank test to take matching into account. Correlation between exposure levels was assessed using Pearson's correlation coefficient.

Cases were categorised into ordered quartiles based on the distribution of exposure in the control population. A further binary variable was created to assess whether blood concentration exceeding 'highly exposed' levels, defined as being above the 90th percentile of the control exposure distribution, was associated with greater risk by comparing it to those in the lowest quartile. For the remaining analyses, stratified by subtype, age group, BMI category and time to diagnosis, exposure levels were log transformed to normalise the distributions.

In the basic model, conditional logistic regression analyses were used to calculate odds ratios and 95\% confidence intervals accounting for the matching factors. Tests for trend were performed using the Wald test statistic based on the continuous quartiles. Where all controls were included to maximise power, unconditional logistic regression adjusting for the matching variables was used. Confounding was assessed by additionally running an adjusted model; potential confounders were identified as BMI $\left(\mathrm{kg} / \mathrm{m}^{2}\right)$, height $(\mathrm{cm})$, educational level (as a proxy for socioeconomic status), vegetable intake (g/day), dairy intake (g/day), protein intake (g/day), total fat intake (g/day) and alcohol consumption (g/day), based on both a significant $(p<0.05)$ association with cumulative
POP concentration in the total population and a reported association with NHL in the literature $[16,17]$ to ensure biological plausibility for the included confounders.

All analyses were performed using Stata 11.3, the level of statistical significance was set at 0.05 and all tests were two tailed.

\section{Results}

A total of 281 incident cases were diagnosed during follow-up; 84 from EPIC Italy and 197 from NSHDS. Only cases of B-cell NHL were included in the final analyses, resulting in the exclusion of six cases of Hodgkin's Lymphoma, one case of T-cell NHL, four cases with unknown subtype and their matched controls $(n=11$ case-control pairs). There were no significant differences between cases and controls for any of the baseline variables investigated (Table 1). The median time from blood collection to diagnosis was 6.6 years in NSHDS and 5.0 years in Epic-Italy, There was no association between time to NHL diagnosis and body burden of any of the pollutants amongst the cases ( $p$-value $>0.05$ ).

The mean, median and range of exposure concentrations in cases and controls for each investigated pollutant are shown in Table 2. There was no significant difference $(p<0.05)$ in median exposure levels between cases and controls according to the Wilcoxon signed rank test for any of the investigated exposures (Table 2). The investigated exposures displayed a strong degree of correlation (Additional file 1: Table S1), particularly amongst those PCBs with similar degrees of chlorination.

For BDE-47 and DDT more than $80 \%$ of the population had levels that could not be quantified and therefore these exposures were excluded from further analyses. There was no significant difference in the proportion of cases and controls above and below the LOQ for either BDE-47 ( $p$ $=0.706)$ or DDT $(p=0.425)$. One participant, a male control from the NSHDS was excluded from the PCB analyses as an outlier as his exposure levels were far above the 99th percentile of the distribution for all congeners.

Table 3 shows the association between increasing quartiles of exposure and risk of NHL, both under the basic conditional model, and when adjusting for potential confounders. Although under the basic model a number of significant inverse associations were observed there was no evidence of a dose-response trend. When adjusting on confounders, PCB138, PCB153, HCB and DDE displayed inverse trends.

Stratified analyses by gender (Table 4) indicated that these inverse associations were heavily influenced by males who displayed multiple dose-dependent inverse trends with the investigated POPs. This was not observed in females. In analyses stratified by cohort (Additional file 1: Table S2) inverse associations with these POPs were restricted to the Swedish cohort. 
Table 1 Baseline characteristics of cases and controls

\begin{tabular}{|c|c|c|c|c|}
\hline Baseline variable & & $\begin{array}{l}\text { Case } \\
(n=270) \\
{[n(\%)]}\end{array}$ & $\begin{array}{l}\text { Control } \\
(n=270) \\
{[n(\%)]}\end{array}$ & $\begin{array}{l}\text { Difference } \\
\text { ( } p \text {-value) }\end{array}$ \\
\hline \multirow[t]{2}{*}{ Cohort } & EPIC-Italy & 84 (31.1) & 84 (31.1) & \\
\hline & NSHDS & $186(68.9)$ & $186(68.9)$ & \\
\hline \multirow[t]{2}{*}{ Sex } & Male & $133(49.3)$ & $133(49.3)$ & \\
\hline & Female & $137(50.7)$ & $137(50.7)$ & \\
\hline Mean Age & (yrs) & 53.08 & 53.09 & 0.989 \\
\hline Mean Height & $(\mathrm{cm})$ & 169.55 & 168.24 & 0.120 \\
\hline Mean Weight & $(\mathrm{kg})$ & 76.48 & 75.09 & 0.267 \\
\hline \multirow[t]{5}{*}{ BMl } & Underweight & $1(0.4)$ & $0(0.0)$ & \\
\hline & Normal & $104(38.5)$ & $109(40.4)$ & \\
\hline & Overweight & $121(44.8)$ & $118(43.7)$ & \\
\hline & Obese & $40(14.8)$ & $39(14.4)$ & \\
\hline & unknown & $4(1.5)$ & $4(1.5)$ & 0.883 \\
\hline \multirow[t]{4}{*}{ Smoking status } & Never & $121(44.8)$ & 134 (49.6) & \\
\hline & Former & $90(33.3)$ & $72(26.7)$ & \\
\hline & Current & $57(21.1)$ & $54(20)$ & \\
\hline & unknown & $2(0.7)$ & $10(3.7)$ & 0.269 \\
\hline \multirow{6}{*}{$\begin{array}{l}\text { Highest educational } \\
\text { level }\end{array}$} & None & $4(1.5)$ & $1(0.4)$ & \\
\hline & Primary & $94(34.8)$ & $98(36.3)$ & \\
\hline & $\begin{array}{l}\text { Technical/ } \\
\text { professional }\end{array}$ & $68(25.2)$ & $54(20.0)$ & \\
\hline & Secondary & $52(19.3)$ & 64 (23.7) & \\
\hline & $\begin{array}{l}\text { University/ } \\
\text { college }\end{array}$ & $47(17.4)$ & $42(15.6)$ & \\
\hline & unknown & $5(1.9)$ & $11(4.1)$ & 0.202 \\
\hline \multirow{5}{*}{$\begin{array}{l}\text { Cambridge physical } \\
\text { activity index }\end{array}$} & Inactive & 80 (29.6) & 75 (27.8) & \\
\hline & $\begin{array}{l}\text { Moderately } \\
\text { inactive }\end{array}$ & $106(39.3)$ & $95(35.2)$ & \\
\hline & $\begin{array}{l}\text { Moderately } \\
\text { active }\end{array}$ & 69 (25.6) & $76(28.2)$ & \\
\hline & Active & $14(5.2)$ & $23(8.5)$ & \\
\hline & unknown & $1(0.4)$ & $1(0.4)$ & 0.510 \\
\hline
\end{tabular}

Chi2 tests excluded the unknown category

Information on histological subtype was available for 225 of 270 cases $(83 \%)$ and the remaining 45 cases were classified as 'B-cell NHL, not otherwise specified'. The most common subtype was Multiple Myeloma (MM), which accounted for $28 \%$ of cases. The associations between log transformed exposure levels and risk for the four largest subgroups are shown in Table 5 . The significant inverse associations were limited to Diffuse Large B-cell Lymphoma (DLBCL). However, when a metaanalyses of each exposure by subtype was conducted, the $\mathrm{I}^{2}$ was $0 \%$ for all exposures except PCB170 (19.1\%) and PCB180 (30.1\%), and the $p$ values were $>0.1$, indicating no significant heterogeneity between the subtypes.
Additional stratified analyses were performed to identify confounders or effect modifiers that may explain the unexpected inverse associations. Neither age at recruitment (and therefore at blood draw; Additional file 1: Table S3) nor time to diagnosis (Additional file 1: Table S4) appeared to be modifying the findings. Results from the meta-analysis indicated that the percentage of heterogeneity not due to chance $\left(\mathrm{I}^{2}\right)$ was $0 \%$ for all exposures, and all $p$-values were non-significant. When subjects were stratified by BMI (Additional file 1: Table S5) there was some indication that risk estimates tended to decrease with BMI category, with the smallest ORs generally noted in obese participants. Effect modification by BMI may also in part explain the observed sex discrepancy, $69.6 \%$ of males were overweight or obese compared with only $50.2 \%$ of females $(p<0.0001)$. However, there was no significant heterogeneity between BMI classes for any of the exposures $(P>0.05)$ and no conclusions can be drawn based on these analyses alone. The ORs were greater than one for PCBs 118, 153, 170 and 180 in individuals whose exposure levels were above the 90th percentile. This could be interpreted to suggest that very high levels may increase risk, however these associations were not significant, (Table 6).

Groups of PCBs based on the properties of the congeners [18] were also analysed together; dioxin-like congeners (PCB\#s 118, 156), non-dioxin like congeners (PCB\#s138, 153, 170, 180) and immunotoxic congeners (PCB\#s118, 138, 156, 170), and the sum total of all PCBs. However, these were driven by the constituent PCBs and significant inverse relationships were noted for the non-dioxin like and immunotoxic groups (results not shown). Categorising subjects into quartiles based on the distribution of exposure levels in the total population and exposure levels in cases only, did not change the findings (results not shown).

\section{Discussion}

Exposure to PCBs and other persistent organic pollutants has been hypothesised to be partly responsible for the increase in NHL observed in the last 30 years $[8,19]$, which is larger than can be explained on the basis of changes to the classification procedures [19] or on known risk factors alone [20]. However the literature is inconclusive [21, 22]. In this study a prospective design was used to explore the risk of NHL associated with internal dose of six PCB congeners, HCB and DDE, under the hypothesis that an elevated body burden may increase future risk of this malignancy. We report geographical and sex-specific differences in results. In this population there was evidence of a possible increase in risk with exposure to certain PCB congeners in females, and a number of unexpected inverse associations in males. Our results additionally suggest possible differences in risk by subtype but these were based 
Table 2 Mean, median and range of exposure concentrations of six PCB congeners, HCB, DDT, DDE and BDE-47

\begin{tabular}{|c|c|c|c|c|c|c|c|c|c|c|}
\hline \multirow[t]{2}{*}{ Exposure } & \multirow[t]{2}{*}{ LOQ } & \multicolumn{4}{|c|}{ Cases $(n=270)$} & \multicolumn{4}{|c|}{$\%$ Controls $(n=270)^{a}$} & \multirow{2}{*}{$\begin{array}{l}\text { Difference } \\
p \text {-value }^{b}\end{array}$} \\
\hline & & $\%<\mathrm{LOQ}$ & Median & Mean & Range & $\%<\mathrm{LOQ}$ & Median & Mean & Range & \\
\hline PCB118 & $5 \mathrm{pg} / \mathrm{ml}$ & $0.0 \%$ & 134.7 & 182 & $(8.5,901.6)$ & $0.0 \%$ & 147.7 & 175.7 & $(11.6,832.1)$ & 0.991 \\
\hline PCB138 & $5 \mathrm{pg} / \mathrm{ml}$ & $0.0 \%$ & 530.0 & 605.6 & $(11.0,1810.1)$ & $0.0 \%$ & 562.3 & 636.4 & $(51.2,2675.4)$ & 0.276 \\
\hline PCB153 & $4 \mathrm{pg} / \mathrm{ml}$ & $0.0 \%$ & 1007.8 & 1150.9 & $(32.5,3308.0)$ & $0.0 \%$ & 1086 & 1205.5 & $(120.6,4334.1)$ & 0.239 \\
\hline PCB156 & $2 \mathrm{pg} / \mathrm{ml}$ & $0.0 \%$ & 90.6 & 102 & $(19.8,307.8)$ & $0.0 \%$ & 95.6 & 106.7 & $(15.5,394.9)$ & 0.186 \\
\hline PCB170 & $4 \mathrm{pg} / \mathrm{ml}$ & $0.0 \%$ & 326.4 & 375.2 & $(62.7,1082.3)$ & $0.0 \%$ & 357.6 & 389.4 & $(50.4,1291.2)$ & 0.284 \\
\hline PCB180 & $3 \mathrm{pg} / \mathrm{ml}$ & $0.0 \%$ & 696.6 & 788.8 & $(139.7,2708.8)$ & $0.0 \%$ & 727.8 & 807.9 & $(100.1,2431.5)$ & 0.284 \\
\hline $\mathrm{HCB}$ & $25 \mathrm{pg} / \mathrm{ml}$ & $0.0 \%$ & 257.8 & 398.1 & $(62.5,3604.0)$ & $0.0 \%$ & 289.2 & 432.5 & $(64.5,3882.2)$ & 0.198 \\
\hline DDT & $200 \mathrm{pg} / \mathrm{ml}$ & $85.9 \%$ & 261.8 & 331.7 & $(206.6,825.8)$ & $86.7 \%$ & 298.2 & 399.8 & $(218.8,1636.9)$ & 0.865 \\
\hline DDE & $5 \mathrm{pg} / \mathrm{ml}$ & $0.0 \%$ & 2478.7 & 4038.4 & $(16.4,30992.8)$ & $0.0 \%$ & 2675.3 & 4200.1 & $(76.4,23858.3)$ & 0.374 \\
\hline BDE-47 & $15 \mathrm{pg} / \mathrm{ml}$ & $84.1 \%$ & 23.5 & 34.2 & $(15.1,133.4)$ & $81.1 \%$ & 25.8 & 95.1 & $(15.3,2063.3)$ & 0.657 \\
\hline
\end{tabular}

LOQ limit of quantification

aPCB analyses were based on 269 controls as one participant with exposure levels above the $99^{\text {th }}$ percentile was excluded

${ }^{b}$ Differences between median concentrations in cases and controls according to the Wilcoxon signed-rank test for paired samples

on small numbers. Stratified analyses revealed no evidence of confounding or effect modification by age at diagnosis or by time between blood draw and disease diagnosis. Those in the very highest levels of exposure showed a non-significantly increased risk for a number of PCBs.

PCBs, a mixture of synthetic chlorinated hydrocarbons that are the products and incidental by-products of multiple industrial and agricultural processes, have recently been upgraded to Class 1 carcinogens by the International Agency for Research on Cancer [23]. Although once widely used, concern about their health effects and toxicity has led to PCBs being banned in most countries [24]. However, these compounds are exceptionally stable, chemically inert and highly soluble in lipids [25]. Consequently they have extensively polluted the environment and are still found in all environmental media, including air, water, and soil which has led to bioaccumulation in the food chain, and most people have a measurable amount of PCBs in their bodies [21].

The evidence for an association with NHL is based on the observed tumorogenic and carcinogenic properties of PCBs, and in particular the dioxin-like properties exhibited by the coplanar congeners [26, 27]. The dioxinlike congeners share a biological mechanism, based on binding to the Ah-receptor [28], with 2,3,7,8-TCDD a compound which has previously been associated with an increased risk of lymphoid malignancies [29]. The association with NHL is further supported by the known immunosupressive and inflammatory properties of PCBs [30], and the temporal relationship between the incidence of NHL and the worldwide production of PCBs.

Although PCBs have been widely explored in relation to NHL, the evidence has been contradictory. While many studies report a positive association with the sum of PCB body burden, PCB mixtures (including dioxinlike, non-dioxin like and immunotoxic) and individual congeners [26, 31-36], an equally large number have found no association [37-43]. Many of the positive findings come from case-control studies which are subject to the problems of reverse causation and other bias, or from investigations of high levels of accidental exposure $[36,44]$. Even among highly exposed occupational cohorts the results have not been consistent [22]. Others have utilised proxies, such as house dust, which may not accurately reflect actual exposure [35]. Of the studies most directly comparable with this study, those utilising prediagnostic exposure measurements in the general population, two $[34,45]$ reported an increased risk with total PCB exposure in both sexes, while a third [32] reported an increase in males. Two further studies [37, 38] reported no significant associations for any of the investigated congeners. Even systematic reviews have been unable to confirm or refute an association, and a causal relationship remains to be defined $[21,22,25,35,45]$.

The literature is similarly inconsistent for DDE and for $\mathrm{HCB}$, which showed some of the strongest inverse associations in this population. Three case control-studies have reported a positive association between NHL and DDE. One was based on adipose tissue concentrations [42] and two measured levels in blood [31, 33]. However, in a study of serum organochlorine levels in participants living near a municipal solid waste incinerator the relationship was borderline significant and the OR indicated only a marginal increase in risk [31]. Additionally a number of both case-control $[26,41]$ and cohort $[32,37,38]$ studies have reported no association. Similarly, for those studies considering HCB; although one [33] observed a positive association with risk, two other studies report null findings [31, 37].

In this study of a general, non-occupationally exposed cohort, exposure was assessed using blood concentrations of eight POPs in samples taken from cancer-free 
Table 3 Association between NHL and quartiles of measured body burden of six PCB congeners, specified PCB functional groups, $\mathrm{HCB}$ and DDE

\begin{tabular}{|c|c|c|c|c|c|c|c|c|c|c|c|}
\hline Exposure & Quartile & n. $\mathrm{Ca}$ & n. Co & OR & $95 \% \mathrm{Cl}$ & $P$-value & $p$ for trend & OR(adj) & $95 \% \mathrm{Cl}$ & $P$-value & $p$ for trend \\
\hline \multirow[t]{4}{*}{$\overline{P C B 118}$} & Q1 $(8.46,94.05)$ & 80 & 68 & 1 & & & & 1 & & & \\
\hline & Q2 $(94.25,148.04)$ & 68 & 67 & 0.76 & $(0.44,1.32)$ & 0.332 & & 0.57 & $(0.31,1.08)$ & 0.084 & \\
\hline & Q3 (148.37, 219.85) & 42 & 66 & 0.45 & $(0.24,0.84)$ & $0.012^{*}$ & & 0.35 & $(0.17,0.72)$ & $0.004^{*}$ & \\
\hline & Q4 (219.91, 901.63) & 80 & 67 & 0.96 & $(0.49,1.87)$ & 0.909 & 0.571 & 0.67 & $(0.3,1.49)$ & 0.332 & 0.168 \\
\hline \multirow[t]{4}{*}{ PCB138 } & Q1 $(10.97,396.03)$ & 86 & 67 & 1 & & & & 1 & & & \\
\hline & Q2 (399.73, 562.09) & 60 & 67 & 0.67 & $(0.41,1.08)$ & 0.102 & & 0.53 & $(0.31,0.91)$ & $0.021^{*}$ & \\
\hline & Q3 $(562.64,778.15)$ & 63 & 67 & 0.63 & $(0.37,1.1)$ & 0.104 & & 0.50 & $(0.27,0.94)$ & $0.031^{*}$ & \\
\hline & Q4 (778.44, 2675.35) & 61 & 67 & 0.60 & $(0.33,1.08)$ & 0.089 & 0.093 & 0.38 & $(0.18,0.78)$ & $0.009^{*}$ & $0.010^{*}$ \\
\hline \multirow[t]{4}{*}{ PCB153 } & Q1 $(32.47,812.10)$ & 88 & 68 & 1 & & & & 1 & & & \\
\hline & Q2 (813.60, 1083.97) & 59 & 66 & 0.60 & $(0.36,1.03)$ & 0.064 & & 0.56 & $(0.31,1.02)$ & 0.058 & \\
\hline & Q3 (1088.49, 1489.97) & 60 & 67 & 0.54 & $(0.3,0.98)$ & $0.044^{*}$ & & 0.47 & $(0.24,0.93)$ & $0.031^{*}$ & \\
\hline & Q4 (1493.70, 4334.12) & 63 & 67 & 0.55 & $(0.3,1.04)$ & 0.066 & 0.078 & 0.37 & $(0.17,0.78)$ & $0.009^{*}$ & $0.011^{*}$ \\
\hline \multirow[t]{4}{*}{ PCB156 } & Q1 $(15.50,69.69 .62)$ & 75 & 67 & 1 & & & & 1 & & & \\
\hline & Q2 $(69.95,95.44)$ & 71 & 67 & 0.88 & $(0.49,1.56)$ & 0.654 & & 0.9 & $(0.48,1.71)$ & 0.754 & \\
\hline & Q3 $(95.76,126.68)$ & 51 & 67 & 0.59 & $(0.31,1.11)$ & 0.100 & & 0.56 & $(0.27,1.16)$ & 0.118 & \\
\hline & Q4 (126.87, 394.89) & 73 & 67 & 0.86 & $(0.45,1.64)$ & 0.644 & 0.545 & 0.69 & $(0.33,1.45)$ & 0.326 & 0.228 \\
\hline \multirow[t]{4}{*}{ PCB170 } & Q1 $(50.39,257.50)$ & 73 & 67 & 1 & & & & 1 & & & \\
\hline & Q2 (257.62, 358.81) & 82 & 68 & 0.99 & $(0.59,1.66)$ & 0.967 & & 0.9 & $(0.51,1.6)$ & 0.718 & \\
\hline & Q3 (359.10, 468.52) & 43 & 66 & 0.48 & $(0.25,0.92)$ & $0.028^{*}$ & & 0.37 & $(0.17,0.79)$ & $0.010^{*}$ & \\
\hline & Q4 (468.55, 1291.23) & 72 & 67 & 0.83 & $(0.45,1.53)$ & 0.55 & 0.356 & 0.59 & $(0.28,1.23)$ & 0.160 & 0.091 \\
\hline \multirow[t]{4}{*}{ PCB180 } & Q1 $(100.08,533.51)$ & 72 & 67 & 1 & & & & 1 & & & \\
\hline & Q2 (533.84, 730.03) & 78 & 68 & 1.03 & $(0.61,1.73)$ & 0.926 & & 1 & $(0.55,1.81)$ & 0.999 & \\
\hline & Q3 (730.81, 966.02) & 46 & 66 & 0.57 & $(0.31,1.05)$ & 0.071 & & 0.45 & $(0.21,0.95)$ & $0.035^{*}$ & \\
\hline & Q4 $(966.55,2708,83)$ & 74 & 67 & 0.94 & $(0.52,1.69)$ & 0.827 & 0.595 & 0.68 & $(0.32,1.42)$ & 0.300 & 0.168 \\
\hline \multirow[t]{4}{*}{$\mathrm{HCB}$} & Q1 $(62.47,181.87)$ & 85 & 67 & 1 & & & & 1 & & & \\
\hline & Q2 $(184.78,288.81)$ & 62 & 67 & 0.58 & $(0.32,1.03)$ & 0.064 & & 0.52 & $(0.27,1.02)$ & 0.057 & \\
\hline & Q3 (289.49, 474.86) & 59 & 67 & 0.47 & $(0.24,0.94)$ & $0.032^{*}$ & & 0.28 & $(0.12,0.65)$ & $0.003^{*}$ & \\
\hline & Q4 (477.00, 3882.19) & 64 & 66 & 0.49 & $(0.22,1.07)$ & 0.074 & 0.061 & 0.35 & $(0.14,0.87)$ & $0.023^{*}$ & $0.014^{*}$ \\
\hline \multirow[t]{4}{*}{ DDE } & Q1 $(16.40,1308.26)$ & 81 & 67 & 1 & & & & 1 & & & \\
\hline & Q2 (1310.23, 2666.60) & 62 & 67 & 0.65 & $(0.37,1.14)$ & 0.137 & & 0.55 & $(0.28,1.05)$ & 0.07 & \\
\hline & Q3 (2675.27, 5523.58) & 68 & 68 & 0.67 & $(0.37,1.21)$ & 0.186 & & 0.40 & $(0.20,0.84)$ & $0.015^{*}$ & \\
\hline & Q4 (5528.29, 30992.76) & 59 & 66 & 0.55 & $(0.28,1.08)$ & 0.082 & 0.106 & 0.34 & $(0.15,0.77)$ & $0.010^{*}$ & $0.008^{*}$ \\
\hline
\end{tabular}

OR - conditional logistic regression accounting for matching factors

$\mathrm{OR}^{(\text {adj) }}$ - conditional logistic regression additionally adjusting for BMI, height, educational level, vegetables, dairy, protein, total fat, alcohol "Significant at the $95 \%$ confidence level

individuals at recruitment to the cohort. This provides a point estimate of historical exposure free from recall bias, which can be common when individuals are surveyed on their long term exposure to environmental pollutants. Additionally, the measure is free from disease bias; pathological changes may affect the levels of certain pollutants and therefore distort the association, but in this study all participants were free of lymphoma at ascertainment. Global restrictions in the use of POPs has led to a reported decrease in human body burden over the last decade: for PCBs current exposure levels are estimated to be half those of 20-30 years ago [46], making it difficult to compare between populations and across periods. However, the observed exposure levels for the POPs were within the range of those reported in studies of similar populations [47]. All POPs, with the exception of PCB170, were at higher levels in the Italian cohort.

In general, inverse associations were noted for males, while females tended to show positive, although nonsignificant associations. Gender-specific differences were 


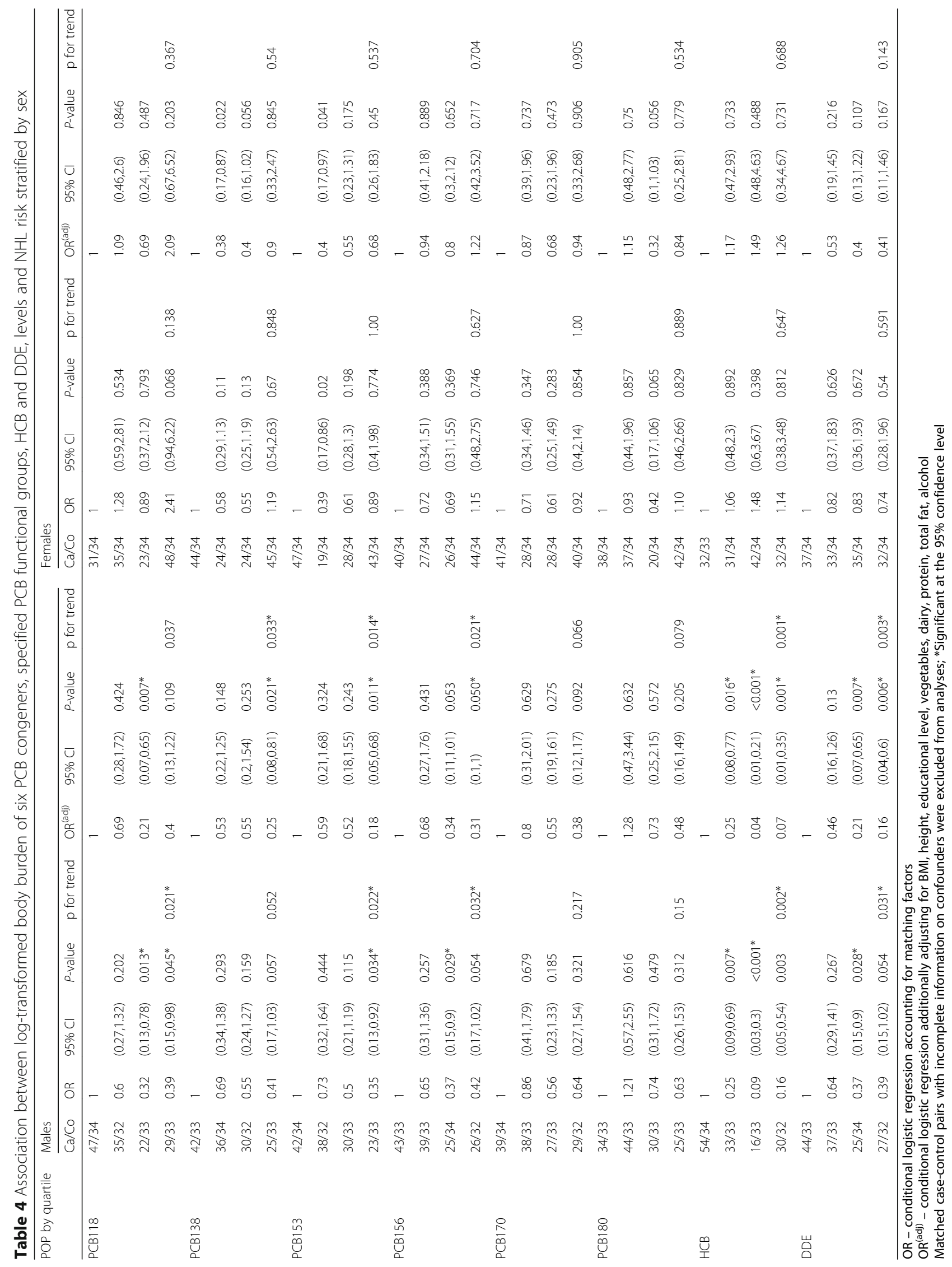


also noted in the studies by Bertrand and Laden [32, 38], however conversely to our findings they report a positive association in males but find no evidence of a relationship in females. Other studies of PCBs have observed no gender differences [34], however analysis of similar organochlorines suggest that sex-specific differences in the uptake, metabolism and elimination of compounds may result in variation in risk effects [37, 48-52] Breast feeding and parity are also likely to play a role [46].

The heterogeneous nature of NHL and the differing composition of subtypes explored in other studies may, in part, explain the differing findings between this study and previous work [42]. A number of the studies did not stratify their results by subtype [8, 9, 31, 34, 37, 40, 42, 45]. Among those that did the strongest associations tended to be noted for DLBCL $[26,32,33]$, with weaker and in some cases (non-significantly) inverse associations reported for FL [26] and SLL/CLL $[32,38]$ in some studies. Even where specific subtypes have been studied the results have been inconsistent between studies. For example, in contrast to much of the literature FL has been reported to be strongly associated with PCBs in at least one study [33], while within a single study differing directions of effect were observed for DLBCL among different geographical populations [41]. Findings are further complicated by reports that subtype-specific associations may also differ by genotype [28] and by $\mathrm{t}(14: 18)$ translocation status [42]. It should be noted that none of the existing studies reported MM as a separate subgroup, as due to its pathophysiological differences MM is often considered a distinct entity from other B-cell NHLs. However under the most commonly used classifications scheme today MM is classed as a B-cell NHL (hierarchical group 4) and therefore in this study was considered with the other B-cell subtypes. In the present study the inverse associations appeared to be driven by cases of DLBCL, however we report no significant evidence of subtype heterogeneity. The differing composition of the PCB congeners included in different studies may also account for some of the observed discrepancy between studies, particularly where a risk effect for the sum of PCBs has been reported. It is also noted that exposure to PCBs and how they are metabolised may differ in an occupational setting as opposed to in the general population [8].

In order to try and further disentangle our findings, a number of additional analyses were performed. To ensure that pre-diagnostic subclinical changes in cases who were diagnosed shortly after blood draw were not modifying the body burden of exogenous exposures [53], stratification by the time to diagnosis was performed. However there was no evidence of an effect, and similarly age at diagnosis did not appear to be modifying the results. There was, however, some weak evidence of an effect of BMI, which may be worthy of further investigation. Risk estimates tended to decrease with BMI category, with the smallest ORs generally noted in obese participants. This may be of interest as organochlorines are stored in adipose tissue and therefore PCB levels in the blood have previously been reported to be inversely associated with weight gain, and overweight and obese individuals have been observed to have lower circulating levels [54]; this may mask an association if POPs are most metabolically active on a tissue level. If BMI does act as a confounder this could explain the high number of inverse associations noted in this population which contained a high proportion $(60 \%)$ of overweight and obese individuals. It would also explain why inverse associations were overrepresented in males, who had a significantly higher proportion of overweight and obese participants. Additional analyses would be required to determine whether BMI was driving the observed gender effects or vice versa. However, as noted in the results there was no significant heterogeneity between BMI classes.

In this study, lipids were not adjusted for as it has been observed that direct standardisation can introduce bias [55], and unadjusted volume-based concentrations of POPs have been found to correlate well with lipid based concentrations [15]. Furthermore, the possibility of 'reverse causation' and disease progression bias [53], which are the main reasons to adjust for lipids, (in order to take physiological pre-cancerous changes to normal metabolic process and lipid mobilisation into account), have been considered in these analyses. However, the findings for BMI suggest that lipid profiles of individuals may be important, and we cannot rule out that the lack of lipid-adjustment may be influencing our results.

The main strength of this study is its prospective design which protects against selection bias and it was determined that the case and control populations were similar with respect to baseline factors and additional confounders. This design also allows for the determination of a temporal and causal relationship between exposure and NHL, lacking in the majority of studies which tend to measure post-diagnostic or post-treatment levels. NHL or its treatment may affect metabolism and blood concentrations of POPs [32, 54], and chemotherapy has been observed to decrease PCB levels in the body by up to $30 \%$ [21]. The measures of exposure assessment were free from recall and disease bias, and were conducted using validated methodologies. The use of blood measurements has been shown to provide a reliable estimate of POP body burden due to their long half-lives [38].

There were several limitations to this study. The high correlation between exposures, particularly the PCBs, restricted the ability to determine individual effects [56]. When multiple POPs were investigated in combination no additional associations were revealed. It is possible that there were further unmeasured confounders affecting the results, for example other organochlorines or 
Table 5 Association between log-transformed body burden of six PCB congeners, specified PCB functional groups, HCB and DDE, levels and NHL risk stratified by Subtype

\begin{tabular}{|c|c|c|c|c|c|c|c|c|c|c|c|c|}
\hline \multirow[t]{2}{*}{ Exposure } & \multicolumn{6}{|c|}{ CLL $(n=42)$} & \multicolumn{6}{|c|}{ DLBCL $(n=45)$} \\
\hline & $\overline{O R}$ & $95 \% \mathrm{Cl}$ & $p$-value & $\mathrm{OR}^{(\mathrm{adj})}$ & $95 \% \mathrm{Cl}$ & $p$-value & $\overline{O R}$ & $95 \% \mathrm{Cl}$ & $p$-value & $O R^{(a d j)}$ & $95 \% \mathrm{Cl}$ & $p$-value \\
\hline PCB118 & 0.70 & $(0.31,1.58)$ & 0.398 & 5.14 & $(0.56,47.08)$ & 0.147 & 0.74 & $(0.27,2.04)$ & 0.561 & 0.39 & $(0.06,2.68)$ & 0.335 \\
\hline PCB138 & 0.63 & $(0.26,1.54)$ & 0.309 & 1.33 & $(0.15,11.91)$ & 0.801 & 0.37 & $(0.10,1.32)$ & 0.126 & 0.33 & $(0.04,2.47)$ & 0.281 \\
\hline PCB153 & 0.50 & $(0.16,1.52)$ & 0.221 & 0.70 & $(0.06,7.77)$ & 0.772 & 0.32 & $(0.08,1.26)$ & 0.103 & 0.16 & $(0.01,1.84)$ & 0.140 \\
\hline PCB156 & 0.57 & $(0.16,2.10)$ & 0.402 & 1.47 & $(0.11,19.75)$ & 0.773 & 0.25 & $(0.06,0.96)$ & $0.044^{*}$ & 0.01 & $(0,0.53)$ & $0.023^{*}$ \\
\hline PCB170 & 0.52 & $(0.16,1.66)$ & 0.267 & 0.34 & $(0.03,3.61)$ & 0.372 & 0.24 & $(0.06,1.02)$ & 0.053 & 0.01 & $(0,0.47)$ & $0.021^{*}$ \\
\hline PCB180 & 0.49 & $(0.14,1.77)$ & 0.278 & 0.27 & $(0.02,4.15)$ & 0.351 & 0.23 & $(0.05,0.97)$ & $0.045^{*}$ & 0.01 & $(0,0.50)$ & $0.020^{*}$ \\
\hline $\mathrm{HCB}$ & 0.42 & $(0.14,1.26)$ & 0.121 & 1.12 & $(0.17,7.40)$ & 0.905 & 0.90 & $(0.34,2.39)$ & 0.834 & 0.41 & $(0.08,2.00)$ & 0.271 \\
\hline DDE & 0.83 & $(0.44,1.58)$ & 0.578 & 1.99 & $(0.52,7.59)$ & 0.313 & 0.88 & $(0.43,1.84)$ & 0.743 & 1.17 & $(0.35,3.97)$ & 0.796 \\
\hline \multirow[t]{2}{*}{ Exposure } & \multicolumn{6}{|c|}{$\mathrm{FL}(n=39)$} & \multicolumn{6}{|c|}{$\mathrm{MM}(n=76)$} \\
\hline & OR & $95 \% \mathrm{Cl}$ & $p$-value & $O R^{b(a d j)}$ & $95 \% \mathrm{Cl}$ & $p$-value & OR & $95 \% \mathrm{Cl}$ & $p$-value & $O R^{b(a d j)}$ & $95 \% \mathrm{Cl}$ & $p$-value \\
\hline PCB1 18 & 0.95 & $(0.41,2.21)$ & 0.904 & 1.04 & $(0.34,3.13)$ & 0.947 & 1.06 & $(0.55,2.07)$ & 0.856 & 0.62 & $(0.23,1.63)$ & 0.330 \\
\hline PCB138 & 0.91 & $(0.31,2.67)$ & 0.865 & 1.17 & $(0.29,4.77)$ & 0.822 & 0.74 & $(0.32,1.70)$ & 0.474 & 0.45 & $(0.15,1.32)$ & 0.145 \\
\hline PCB153 & 0.94 & $(0.29,3.04)$ & 0.918 & 1.20 & $(0.27,5.31)$ & 0.814 & 0.73 & $(0.29,1.85)$ & 0.512 & 0.41 & $(0.12,1.42)$ & 0.159 \\
\hline PCB156 & 0.99 & $(0.32,3.01)$ & 0.979 & 1.12 & $(0.24,5.36)$ & 0.885 & 0.77 & $(0.31,1.88)$ & 0.561 & 0.47 & $(0.14,1.62)$ & 0.234 \\
\hline PCB170 & 1.39 & $(0.43,4.51)$ & 0.580 & 1.65 & $(0.33,8.24)$ & 0.540 & 0.77 & $(0.30,2.00)$ & 0.588 & 0.42 & $(0.11,1.66)$ & 0.216 \\
\hline PCB180 & 1.43 & $(0.44,4.63)$ & 0.553 & 1.52 & $(0.31,7.41)$ & 0.605 & 0.90 & $(0.35,2.31)$ & 0.834 & 0.56 & $(0.15,2.10)$ & 0.392 \\
\hline $\mathrm{HCB}$ & 0.82 & $(0.36,1.86)$ & 0.633 & 0.83 & $(0.25,2.70)$ & 0.752 & 0.70 & $(0.30,1.61)$ & 0.394 & 0.31 & $(0.08,1.19)$ & 0.089 \\
\hline DDE & 0.77 & $(0.41,1.48)$ & 0.437 & 0.93 & $(0.34,2.55)$ & 0.885 & 0.66 & $(0.37,1.15)$ & 0.142 & 0.52 & $(0.25,1.10)$ & 0.086 \\
\hline
\end{tabular}

Results for the four largest subtype groups were included

$\mathrm{OR}$ - conditional logistic regression accounting for matching factors

$\mathrm{OR}^{(\text {adj) }}$ - conditional logistic regression additionally adjusting for BMI, height, educational level, vegetables, dairy, protein, total fat, alcohol

"Significant at the $95 \%$ confidence level; Matched case-control pairs with incomplete information on potential confounders were excluded from the

adjusted analyses

dioxins [45] which may bioaccumulate in parallel with the exposures of interest. Furthermore variables relating to the immune system, such as EBV antigens which have been shown to interact with organochlorines in NHL risk [39] can also not be accounted for. The estimate of body burden is based on a single one spot exposure measurement that is not necessarily representative of lifetime exposure. Finally, the generalizability of these findings to other populations should be considered, given the relative overrepresentation of females, the excess of MM cases and the relatively high proportion of overweight participants. In particular, these findings should not be extrapolated into an occupational setting.

Table 6 Association between exposure and risk in 'highly exposed' individuals high exposure is defined as exposure levels above the $90^{\text {th }}$ of the control exposure distribution, the odds of disease are compared with those in the lowest quartile of exposure

\begin{tabular}{lcllllllll}
\hline Exposure & $\begin{array}{l}\text { 90th percentile control } \\
\text { exposure distribution }\end{array}$ & $\begin{array}{l}n \text { cases (\%) above } \\
90^{\text {th }} \text { percentile }\end{array}$ & $\begin{array}{l}n \text { controls(\%) above } \\
90^{\text {th }} \text { percentile }\end{array}$ & OR & $95 \%$ Cl & $p$-value & OR $^{\text {(adj) }}$ & 95\% Cl & $p$-value \\
\hline PCB118 & 316.2 & $35(13.0)$ & $28(10.4)$ & 1.37 & $(0.76,2.45)$ & 0.294 & 1.25 & $(0.65,2.41)$ & 0.500 \\
PCB138 & 1112.4 & $25(9.3)$ & $29(10.7)$ & 0.83 & $(0.45,1.52)$ & 0.550 & 0.81 & $(0.40,1.64)$ & 0.562 \\
PCB153 & 1965.7 & $29(10.7)$ & $29(10.7)$ & 1.01 & $(0.56,1.81)$ & 0.987 & 1.15 & $(0.58,2.26)$ & 0.693 \\
PCB156 & 176.4 & $23(8.5)$ & $28(10.4)$ & 0.79 & $(0.43,1.45)$ & 0.447 & 0.89 & $(0.43,1.81)$ & 0.739 \\
PCB170 & 626.6 & $29(10.7)$ & $29(10.7)$ & 1.00 & $(0.57,1.78)$ & 0.989 & 1.07 & $(0.55,2.06)$ & 0.843 \\
PCB180 & 1323.3 & $29(10.7)$ & $28(10.4)$ & 1.05 & $(0.58,1.88)$ & 0.872 & 1.11 & $(0.57,2.14)$ & 0.763 \\
HCB & 872.8 & $25(9.3)$ & $29(10.7)$ & 0.80 & $(0.41,1.55)$ & 0.506 & 0.84 & $(0.42,1.68)$ & 0.624 \\
DDE & 9787.7 & $27(10)$ & $28(10.4)$ & 0.95 & $(0.50,1.80)$ & 0.878 & 1.01 & $(0.52,1.97)$ & 0.978 \\
\hline
\end{tabular}

$\mathrm{OR}$ - conditional logistic regression accounting for matching factors

$\mathrm{OR}^{(\mathrm{adj})}$ - conditional logistic regression additionally adjusting for BMI, height, educational level, vegetables, dairy, protein, total fat, alcohol

Matched case-control pairs with incomplete information on potential confounders were excluded from the adjusted analyses 
These limitations may in part explain the unexpected nature of a number of the findings. However, there is some precedent in the literature. A study in Finland has previously suggested that dioxins may act on the risk of softtissue sarcoma through a J-shaped dose response curve, and there in some support from animal models for such a relationship [57]. The results of the 'high exposure' analysis could considered to be supportive of a J-shaped curve, however again these results were non-significant, and the results from the quartile analysis do not support this hypothesis within the confines of the exposure levels in this study population.

\section{Conclusion}

In conclusion, we report no evidence that a higher body burden of PCBs, DDE or HCB increased the risk of subsequent NHL diagnosis. Significantly inverse associations were noted for males with a number of the investigated POPs. Despite extensive analyses we were unable to explain these associations. We additionally note that the associated $p$-values would not be robust for multiple testing, and that for the highest levels of exposure the relationship was null. This study adds to the existing body of literature and the results do not support a role for PCBs, DDE and HCB as risk factors for NHL.

\section{Additional file}

Additional file 1: Tables S1-S5 with additional results can be found in the Additional file documents; RKelly_Additional_files.docx. (DOCX 72 kb)

\section{Abbreviations}

BDE-47: 2,2',4,4'-Tetrabromodiphenyl ether; BMI: Body mass index; CLL/ SLL: Chronic lymphocytic leukemia/ small lymphocytic lymphoma; DDE: Dichlorodiphenyldichloroethylene; DDT: Dichlorodiphenyltrichloroethane; DLBCL: Diffuse large B-cell lymphoma; EPIC: European Prospective Investigation into Cancer; FL: Follicular lymphoma; GC: Gas chromatography; HCB: Hexachlorobenzene; HCH: hexachlorocyclohexane; LOQ: Limit of quantification; MM: Multiple myeloma; MS: Mass spectrometry; NHL: NonHodgkin lymphoma; NSHDS: Northern Sweden Health and Disease Study; PCB: Polychlorinated biphenyl; POP: Persistent organic pollutant: SEER: Surveillance, epidemiology, and end results program

\section{Acknowledgements}

The authors wish to thank all the centres and participants who took part in the study and the additional members of the EnviroGenoMarkers Consortium. For further information on the EnviroGenoMarkers Consortium please visit http://www.envirogenomarkers.net/ Additional members of the EnviroGenoMarkers Consortium are: Hector C. Keun ${ }^{a, j}$, Toby J. Athersuch ${ }^{a, j}$, Karin vanVeldhoven ${ }^{a}$, Bo Jonsson ${ }^{b}$, Beatrice Melin ${ }^{f}$, Per Lenner ${ }^{f}$, Panagiotis Georgiadis ${ }^{g}$, Christina Papadopoulou ${ }^{g}$, Aristotelis Chatziioannou ${ }^{9}$, loannis Valavanis ${ }^{9}$, Carlotta Sacerdote ${ }^{h}$, Lützen Portengen', Fatemeh Saberi-Hosnijeh', Dennie G.A.J. Hebels ${ }^{k}$, Jos C.S. Kleinjansk, Theo M.C.M. de Kokk, Ralph Gottschalkk, Danitsja van Leeuwenk, Leen Timmermans', Göran Hallmans', Benedetta Bendinellim, Vittorio Kroghn', Rosario Tumino ${ }^{\circ}$, Salvatore Panico ${ }^{p}$, Manolis Kogevinas ${ }^{q}$, Euripides G. Stephanour, Antonis Myridakis', Lucia Fazzos', Marco De Santiss, Pietro Combas, Panu Rantakokkot, Riikka Airaksinen ${ }^{t}$, Päivi Ruokojärvit, Mark Gilthorpe ${ }^{\mathrm{u}}$, Sarah Fleming ${ }^{\mathrm{u}}$, Thomas Flemingu, Yu-Kang Tu", Wei J. Chenv', Wen-Chung Leev, Chuhsing Kate Hsiaov, Kuo-Liong Chien, Po-Hsiu Kuov, Hung Hung ${ }^{\vee}$, Shu-Fen Liaov, Thoma Lundhw
Affiliations: ${ }^{j}$ Imperial College London, Biomolecular Medicine, Department of Surgery and Cancer, London, UK; ${ }^{k}$ Department of Toxicogenomics, Maastricht University, Maastricht, The Netherlands; 'Nutrition Research, Department of Public Health and Clinical Medicine, Umeå University, Umeå, Sweden; ${ }^{\mathrm{m}}$ Molecular and Nutritional Epidemiology Unit, Cancer Prevention and Research Institute (ISPO), Florence, Italy; ${ }^{n}$ Epidemiology and Prevention Unit, Fondazione IRCCS Istituto Nazionale dei Tumori, Milan, Italy; ${ }^{\circ}$ Cancer Registry and Histopathology Unit, "Civile - M.P. Arezzo" Hospital, Ragusa, Italy; ${ }^{P}$ Department of Clinical and Experimental Medicine, Federico II University, Naples, Italy; ${ }^{9}$ Centre for Research in Environmental Epidemiology (CREAL), Barcelona, Spain; ${ }^{r}$ Environmental Chemical Processes Laboratory, University of Crete, Heraklion, Greece; ${ }^{s}$ Istituto Superiore di Sanita, Rome, Italy; ${ }^{\mathrm{t}}$ National Institute for Health and Welfare, Neulanen Research Centre, Kuopio, Finland; " Leeds Institute of Genetics, Health and Therapeutics, University of Leeds, Leeds, UK; ${ }^{\vee}$ Graduate Institute of Epidemiology and Preventative Medicine, National Taiwan University, Taipei, Taiwan; w Department of Occupational and Environmental Medicine, Lund University Hospital, Lund, Sweden

\section{Funding}

This research was supported by the European Union (Grant agreement 226756 to S.A. Kyrtopoulos). The funders had no role in study design, data collection and analysis, decision to publish, or preparation of the manuscript.

\section{Availability of data and material}

The study reported in the current manuscript was conducted on subjects from two cohorts, one of which is the Northern Sweden Health and Disease Study. The Swedish Personal Data Act (http://www.datainspektionen.se/in-english/ legislation/the-personal-data-act/) prohibits publication of personal data on Swedish subjects, even if anonymized, as long as a code key, or a similar set of identifiable data, exists making back-identification possible, even if that can only be done by an authorized person. This prevents us from making the data on the Swedish subjects available via a public repository and we request that we be exempted from this obligation. If the paper is accepted for publication we will deposit the data on subjects from EPIC Italy, for which no analogous prohibition exists.

\section{Authors' contributions}

SAK and PV conceived of the original study. RSK performed the statistical analysis and wrote the manuscript. HK performed the PCB/DDE/HCB measurement analyses. DP coordinated the Italian cases, IAB and AJ coordinated the Swedish cases. MB, RV and MCH supported the statistical analysis. All authors critically revised the manuscript. All authors read and approved the final manuscript.

\section{Competing interests}

The authors declare that they have no competing interests.

\section{Consent for publication}

Not applicable.

\section{Ethics approval and consent to participate}

This study was approved by the committees on research ethics in Umea (Dnr 08-215 M) and in Florence (ref 347/2009) in accordance with the Declaration of Helsinki of the World Medical Association. All participants provided written consent at recruitment.

\footnotetext{
Author details

${ }^{1}$ Channing Division of Network Medicine, Department of Medicine, Brigham and Women's Hospital and Harvard Medical School, 181 Longwood Avenue, Boston, MA 02115, USA. ²Department of Epidemiology and Biostatistics, Imperial College London, London, UK. ${ }^{3}$ National Institute for Health and Welfare Chemicals and Health Unit, Neulanen Research Centre, Neulaniementie 4, Fl-70210 Kuopio, Finland. ${ }^{4}$ Occupational and Environmental Medicine, Department of Public Health and Clinical Medicine, Umeå University, Umeå, Sweden. ${ }^{5}$ Molecular and Nutritional Epidemiology Unit, Cancer Prevention and Research Institute (ISPO), Florence, Italy. ${ }^{6}$ Department of Radiation Sciences, Oncology, Umeå University, Umeå, Sweden. ${ }^{7}$ National Hellenic Research Foundation, Institute of Biology, Pharmaceutical Chemistry and Biotechnology, Athens, Greece. ${ }^{8} \mathrm{HuGeF}$
} 
Foundation, Turin, Italy. Institute for Risk Assessment Sciences, Division of Environmental Epidemiology, Utrecht University, Utrecht, The Netherlands.

\section{Received: 1 October 2016 Accepted: 7 February 2017} Published online: 16 February 2017

\section{References}

1. Mead GM. ABC of clinical haematology: Malignant lymphomas and chronic lymphocytic leukaemia. BMJ. 1997;314(7087):1103.

2. Teras LR, DeSantis CE, Cerhan JR, Morton LM, Jemal A, Flowers CR. 2016 US lymphoid malignancy statistics by World Health Organization subtypes. CA: A Cancer Journal for Clinicians 2016:n/a-n/a.

3. Zhang Y, Dai Y, Zheng T, Ma S. Risk Factors of non-Hodgkin lymphoma. Expert Opin Med Diagn. 2011;5(6):539-50.

4. Lan Q, Zheng T, Rothman N, Zhang Y, Wang SS, Shen M, Berndt SI, Zahm SH, Holford TR, Leaderer B, et al. Cytokine polymorphisms in the Th1/Th2 pathway and susceptibility to non-Hodgkin lymphoma. Blood. 2006;107(10):4101-8.

5. Saberi Hosnijeh F, Krop EJM, Scoccianti C, Krogh V, Palli D, Panico S, Tumino R, Sacredote C, Nawroly N, Portengen L, et al. Plasma cytokines and future risk of non-Hodgkin lymphoma (NHL): a case-control study nested in the Italian European Prospective Investigation into Cancer and Nutrition. Cancer Epidemiol Biomarkers Prev. 2010;19(6):1577-84

6. Grulich AE, Vajdic CM, Falster MO, Kane E, Smedby KE, Bracci PM, de Sanjose S, Becker N, Turner J, Martinez-Maza O, et al. Birth order and risk of non-Hodgkin lymphoma - true association or bias? Am J Epidemiol. 2010;172(6):621-30.

7. Chiu BC-H, Hou N. Epidemiology and Etiology of Non-Hodgkin Lymphoma. In: Evens MA, Blum AK, editors. Non-Hodgkin Lymphoma: Pathology, Imaging, and Current Therapy. Cham: Springer International Publishing; 2015. p. 1-25.

8. Kramer S, Hikel SM, Adams K, Hinds D, Moon K. Current status of the epidemiologic evidence linking polychlorinated biphenyls and non-hodgkin lymphoma, and the role of immune dysregulation. Environ Health Perspect. 2012;120(8):1067-75

9. Ramis R, Diggle P, Boldo E, Garcia-Perez J, Fernandez-Navarro P, LopezAbente $G$. Analysis of matched geographical areas to study potential links between environmental exposure to oil refineries and non-Hodgkin lymphoma mortality in Spain. Int J Health Geogr. 2012;11:4.

10. Kelly RS, Lundh T, Porta M, Bergdahl IA, Palli D, Johansson A-S, Botsivali M, Vineis $P$, Vermeulen R, Kyrtopoulos SA, et al. Blood erythrocyte concentration of cadmium and lead and the risk of B-cell non-hodgkin's lymphoma and multiple myeloma: a nested case-control study. PLoS One. 2013:8(11), e81892.

11. Chadeau-Hyam M, Athersuch TJ, Keun HC, De lorio M, Ebbels TMD, Jenab M, Sacerdote C, Bruce SJ, Holmes E, Vineis P. Meeting-in-the-middle using metabolic profiling - a strategy for the identification of intermediate biomarkers in cohort studies. Biomarkers. 2011;16(1):83-8.

12. Palli D, Berrino F, Vineis $P$, Tumino R, Panico S, Masala G, Saieva C, Salvini S, Ceroti M, Pala V, et al. A molecular epidemiology project on diet and cancer: the EPIC-Italy prospective study. design and baseline characteristics of participants. Tumori. 2003;89(6):586-93.

13. Hallmans $G$, Agren A, Johansson G, Johansson A, Stegmayr B, Jansson JH, Lindahl B, Rolandsson O, Soderberg S, Nilsson M, et al. Cardiovascular disease and diabetes in the Northern Sweden Health and Disease Study Cohort - evaluation of risk factors and their interactions. Scand J Public Health Suppl. 2003;61:18-24.

14. Fritz A PC, Jack A, Shanmugaratnam $k$, Sobin L, Parkin DM. International Classification of Diseases for Oncology (ICD-O). In. Edited by WHO, Third edn. Geneva: World Health Organisation; 2000.

15. Rylander L, Björkdahl C-M, Axmon A, Giwercman A, Jönsson BAG, Lindh C, Rignell-Hydbom A. Very high correlations between fresh weight and lipidadjusted PCB-153 serum concentrations: Irrespective of fasting status, age, body mass index, gender, or exposure distributions. Chemosphere. 2012; 88(7):828-31.

16. Britton JA, Khan AE, Rohrmann S, Becker N, Linseisen J, Nieters A, Kaaks R, Tjonneland A, Halkjaer J, Severinsen MT, et al. Anthropometric characteristics and non-Hodgkin's lymphoma and multiple myeloma risk in the European Prospective Investigation into Cancer and Nutrition (EPIC). Haematologica. 2008;93(11):1666-77.

17. Alexander DD, Mink PJ, Adami H-O, Chang ET, Cole P, Mandel JS, Trichopoulos D. The non-Hodgkin lymphomas: a review of the epidemiologic literature. Int J Cancer. 2007;120(S12):1-39.
18. Warner J, Osuch JR, Karmaus W, Landgraf JR, Taffe B, O'Keefe M, Mikucki D, Haan P. Common classification schemes for PCB congeners and the gene expression of CYP17, CYP19, ESR1 and ESR2. Sci Total Environ. 2012;414:81-9.

19. Groves FD, Linet MS, Travis LB, Devesa SS. Cancer surveillance series: nonHodgkin's lymphoma incidence by histologic subtype in the United States from 1978 through 1995. J Natl Cancer Inst. 2000;92(15):1240-51.

20. Fisher SG, Fisher RI. The epidemiology of non-Hodgkin's lymphoma. Oncogene. 2004;23(38):6524-34.

21. Freeman MK, Kohles SS. Plasma levels of polychlorinated biphenyls, nonHodgkin lymphoma, and causation. Journal of Environmental and Public Health. 2012;2012:15.

22. Golden R, Kimbrough R. Weight of evidence evaluation of potential human cancer risks from exposure to polychlorinated biphenyls: an update based on studies published since 2003. Crit Rev Toxicol. 2009;39(4):299-331.

23. Lauby-Secretan B, Loomis D, Grosse Y, Ghissassi FE, Bouvard V, BenbrahimTallaa L, Guha N, Baan R, Mattock H, Straif K. Carcinogenicity of polychlorinated biphenyls and polybrominated biphenyls. Lancet Oncol. 2013;14(4):287-8.

24. Baccarelli A, Hirt C, Pesatori AC, Consonni D, Patterson DG, Bertazzi PA, Dölken $\mathrm{G}$, Landi MT. t(14;18) translocations in lymphocytes of healthy dioxin-exposed individuals from Seveso. Italy Carcinogenesis. 2006;27(10):2001-7.

25. Kimbrough RD, Doemland ML, Mandel JS. A mortality update of male and female capacitor workers exposed to polychlorinated biphenyls. J Occup Environ Med. 2003:45(3):271-82.

26. De Roos AJ, Hartge P, Lubin JH, Colt JS, Davis S, Cerhan JR, Severson RK, Cozen W, Patterson DG, Needham LL, et al. Persistent organochlorine chemicals in plasma and risk of non-Hodgkin's lymphoma. Cancer Res. 2005;65(23):11214-26.

27. Faroon OM, Keith S, Jones D, De Rosa C. Carcinogenic effects of polychlorinated biphenyls. Toxicol Ind Health. 2001;17(2):41-62.

28. Ng CH, Janoo-Gilani R, Sipahimalani P, Gallagher RP, Gascoyne RD, Connors JM Weber JP, Lai AS, Leach S, Le ND, et al. Interaction between organochlorines and the AHR gene, and risk of non-Hodgkin lymphoma. Cancer Causes Control. 2010;21(1):11-22.

29. Consonni D, Pesatori AC, Zocchetti C, Sindaco R, D'Oro LC, Rubagotti M, Bertazzi PA. Mortality in a population exposed to dioxin after the Seveso, Italy, accident in 1976: 25 years of follow-up. Am J Epidemiol. 2008;167(7): $847-58$.

30. Strauss HS, Heiger-Bernays W. Methodological limitations may prevent the observation of non-Hodgkin's lymphoma in bioassays of polychlorinated biphenyls. Toxicol Pathol. 2012;40(7):995-1003.

31. Viel J-F, Floret N, Deconinck E, Focant J-F, De Pauw E, Cahn J-Y. Increased risk of non-Hodgkin lymphoma and serum organochlorine concentrations among neighbors of a municipal solid waste incinerator. Environ Int. 2011; 37(2):449-53.

32. Bertrand KA, Spiegelman D, Aster JC, Altshul LM, Korrick SA, Rodig SJ, Zhang SM, Kurth T, Laden F. Plasma organochlorine levels and risk of non-Hodgkin lymphoma in a cohort of men. Epidemiology. 2010;21(2):172-80. doi:10. 1097/EDE.1090b1013e3181cb1610b.

33. Spinelli JJ, Ng CH, Weber J-P, Connors JM, Gascoyne RD, Lai AS, BrooksWilson AR, Le ND, Berry BR, Gallagher RP. Organochlorines and risk of nonHodgkin lymphoma. Int J Cancer. 2007;121(12):2767-75.

34. Rothman N, Cantor KP, Blair A, Bush D, Brock JW, Helzlsouer K, Zahm SH, Needham LL, Pearson GR, Hoover RN, et al. A nested case-control study of non-Hodgkin lymphoma and serum organochlorine residues. Lancet. 1997; 350(9073):240-4

35. Czarnota J, Gennings C, Colt JS, De Roos AJ, Cerhan JR, Severson RK, Hartge $\mathrm{P}$, Ward $\mathrm{MH}$, Wheeler DC. Analysis of environmental chemical mixtures and non-Hodgkin lymphoma risk in the NCl-SEER NHL study. Environ Health Perspect. 2015;123(10):965-70.

36. Zani C, Toninelli G, Filisetti B, Donato F. Polychlorinated biphenyls and cancer: an epidemiological assessment. J Environ Sci Health C Environ Carcinog Ecotoxicol Rev. 2013;31(2):99-144.

37. Brauner EV, Sorensen M, Gaudreau E, LeBlanc A, Eriksen KT, Tjonneland A, Overvad K, Raaschou-Nielsen O. A prospective study of organochlorines in adipose tissue and risk of nonHodgkin lymphoma. Environ Health Perspect. 2012:120(1):105-11.

38. Laden F, Bertrand KA, Altshul L, Aster JC, Korrick SA, Sagiv SK. Plasma organochlorine levels and risk of non-Hodgkin lymphoma in the Nurses' Health study. Cancer Epidemiol Biomarkers Prev. 2010;19(5):1381-4.

39. Hardell $K$, Carlberg M, Hardell L, Bjornfoth $H$, Ericson Jogsten I, Eriksson M, Van Bavel B, Lindstrom G. Concentrations of organohalogen compounds 
and titres of antibodies to Epstein-Barr virus antigens and the risk for nonHodgkin lymphoma. Oncol Rep. 2009;21(6):1567-76.

40. Cantor KP, Strickland PT, Brock JW, Bush D, Helzlsouer K, Needham LL, Zahm $\mathrm{SH}$, Comstock GW, Rothman N. Risk of non-Hodgkin's lymphoma and prediagnostic serum organochlorines: beta-hexachlorocyclohexane, chlordane/heptachlor-related compounds, dieldrin, and hexachlorobenzene. Environ Health Perspect. 2003;111(2):179-83.

41. Cocco P, Brennan P, Ibba A, de Sanjosé LS, Maynadié M, Nieters A, Becker N, Ennas MG, Tocco MG, Boffetta P. Plasma polychlorobiphenyl and organochlorine pesticide level and risk of major lymphoma subtypes. Occup Environ Med. 2008; 65(2):132-40.

42. Quintana PJ, Delfino RJ, Korrick S, Ziogas A, Kutz FW, Jones EL, Laden F, Garshick E. Adipose tissue levels of organochlorine pesticides and polychlorinated biphenyls and risk of non-Hodgkin's lymphoma. Environ Health Perspect. 2004; 112(8):854-61.

43. Ruder AM, Hein MJ, Hopf NB, Waters MA. Mortality among 24,865 workers exposed to polychlorinated biphenyls (PCBs) in three electrical capacitor manufacturing plants: a ten-year update. Int J Hyg Environ Health. 2014;217: 176-87.

44. Alcock RE, Behnisch PA, Jones KC, Hagenmaier H. Dioxin-like PCBs in the environment - human exposure and the significance of sources. Chemosphere. 1998:37(8):1457-72.

45. Engel LS, Lan Q, Rothman N. Polychlorinated biphenyls and non-Hodgkin lymphoma. Cancer Epidemiol Biomarkers Prev. 2007;16(3):373-6.

46. Fernandez MF, Kiviranta H, Molina-Molina JM, Laine O, Lopez-Espinosa MJ, Vartiainen T, Olea N. Polychlorinated biphenyls (PCBs) and hydroxy-PCBs in adipose tissue of women in Southeast Spain. Chemosphere. 2008;71(6): 1196-205.

47. Porta M, Pumarega J, Gasull M. Number of persistent organic pollutants detected at high concentrations in a general population. Environ Int. 2012; 44:106-11.

48. Soucek P, Šarmanová J, Kristensen V, Apltauerová M, Gut I. Genetic polymorphisms of biotransformation enzymes in patients with Hodgkin's and non-Hodgkin's lymphomas. Int Arch Occup Environ Health. 2002;75(1):86-92.

49. Sarmanová J, Benesová K, Gut I, Nedelcheva-Kristensen V, Tynková L, Soucek P. Genetic polymorphisms of biotransformation enzymes in patients with Hodgkin's and non-Hodgkin's lymphomas. Hum Mol Genet. 2001;10(12): 1265-73.

50. De Roos AJ, Gold LS, Wang S, Hartge P, Cerhan JR, Cozen W, Yeager M, Chanock S, Rothman N, Severson RK. Metabolic Gene Variants and Risk of Non-Hodgkin's Lymphoma. Cancer Epidemiol Biomarkers Prev. 2006;15(9): 1647-53.

51. Gra OA, Glotov AS, Nikitin EA, Glotov OS, Kuznetsova VE, Chudinov AV, Sudarikov AB, Nasedkina TV. Polymorphisms in xenobiotic-metabolizing genes and the risk of chronic lymphocytic leukemia and non-Hodgkin's lymphoma in adult Russian patients. Am J Hematol. 2008;83(4):279-87.

52. Kerridge I, Lincz L, Scorgie F, Hickey D, Granter N, Spencer A. Association between xenobiotic gene polymorphisms and non-Hodgkin's lymphoma risk. Br J Haematol. 2002;118(2):477-81.

53. Porta M. Role of organochlorine compounds in the etiology of pancreatic cancer: a proposal to develop methodological standards. Epidemiology. 2001;12(2):272-6.

54. Baris D, Kwak LW, Rothman N, Wilson W, Manns A, Tarone RE, Hartge P. Blood levels of organochlorines before and after chemotherapy among non-Hodgkin's lymphoma patients. Cancer Epidemiol Biomarkers Prev. 2000;9(2):193-7.

55. Gaskins AJ, Schisterman EF. The effect of lipid adjustment on the analysis of environmental contaminants and the outcome of human health risks. Methods Mol Biol. 2009;580:371-81.

56. Aronson KJ, Miller AB, Woolcott CG, Sterns EE, McCready DR, Lickley LA, Fish EB, Hiraki GY, Holloway C, Ross T, et al. Breast adipose tissue concentrations of polychlorinated biphenyls and other organochlorines and breast cancer risk. Cancer Epidemiol Biomarkers Prev. 2000;9(1):55-63.

57. Tuomisto J, Pekkanen J, Kiviranta H, Tukiainen E, Vartiainen T, Viluksela M, Tuomisto JT. Dioxin cancer risk - example of hormesis? Dose-Response. 2005;3(3):332-41.

\section{Submit your next manuscript to BioMed Central and we will help you at every step:}

- We accept pre-submission inquiries

- Our selector tool helps you to find the most relevant journal

- We provide round the clock customer support

- Convenient online submission

- Thorough peer review

- Inclusion in PubMed and all major indexing services

- Maximum visibility for your research

Submit your manuscript at www.biomedcentral.com/submit
C Biomed Central 